\title{
Inventory Reduction in the Supply Chain of Finished Products for Multinational Companies
}

\author{
Amelec Viloria ${ }^{1}$ and Paula Viviana Robayo ${ }^{2^{*}}$ \\ 'Universidad de la Costa, Colombia, Barranquilla, Colombia; \\ aviloria7@cuc.edu.co \\ 2Escuela de Negocios de la Fundación Universitaria Konrad Lorenz, Bogotá, Colombia; \\ paulav.robayoa@konradlorenz.edu.co
}

\begin{abstract}
Objectives: This article aims to propose strategies to reduce inventories in the chain supplies multinational companies finished product. Methods/Statistical analysis: For this a methodology in which one of the largest companies flush commoditization of the world with presence in Europe, Middle East and Africa was studied it was established. Through analysis of reports, and business interviews diagnosed and identifies high inventory levels and inventory policies inadequate as key factors that improve the Supply Chain (SC) of the study sample. Findings: Also they formulated and implemented processes of redistribution and unproductive inventory forecast to combat deteriorations, as well as designing processes to be executed to deepen them. Application/Improvements: The end result is achieved reduce inventory in more than a means of Currency Units (CU) million and, in addition to identifying future risks that might jeopardize service levels of the company.
\end{abstract}

Keywords: Inventory Management, Non - Productive Inventory, Supply Chain Finished Product

\section{Introduction}

The inventory takes up space, prolongs the waiting time production generates transport and storage needs, and absorbs financial assets. Materials, work in process and finished products that take up space in the factory or in the stores do not generate any added value, but on the contrary, they are demotion $\mathrm{n}$ and may even become obsolete quickly. Therefore, one of the biggest concerns that companies have for their operations is the reduction of inventory. However, it often happens that when trying to reduce inventory other issues that directly impact the level of customer service, such as product availability are neglected. That is why high - performance businesses are working to maintain a balance between reducing inventory and service provided to customers through the accuracy, communication and teamwork 1 .

Through analysis of business reports and interviews, this article aims to propose strategies to reduce inventories in the SC of finished product (PUC) multinational companies. For this sample is studied as one of the largest producers of consumer goods in the world whose SC extends throughout Europe, the Middle East and Africa (EMEA).

\section{Theoretical Foundation}

As shown in Figure 1. SC encompasses all activities associated with the flow and transformation of goods and

${ }^{*}$ Author for correspondence 
associated information from the fa of raw materials to the thin user 1. It is essentially a set of connected suppliers and customers; where each customer is in turn the next provider organization "downstream" until the finished product reaches the end user².

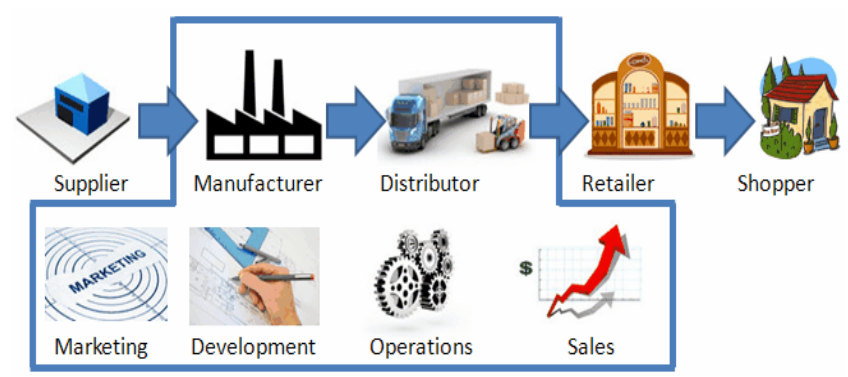

Figure 1. Traditional supply chain ${ }^{3}$.

Today, it seems evident the obsolescence of the industrial paradigm based on optimizing the processes of the SC as if they were isolated functions aimed outside $r$ optimizes its efficiency and stability. Companies must evolve from that endogenic industrial approach based on the internal efficiency of processes oriented on the added value given to customers with an overview of the chain paradigm ${ }^{4}$.

The factor that catalyses all these changes is undoubtedly the increase in an increasingly demanding and personalized customer demand. In addition, global competition stimulates this change and force manufacturers to find new ways to produce more in line with the changing needs and personalized market, the same time keep the costs as low as possible. All this is forcing companies to find new ways of collaboration to improve the integration and synchronization of the various functions and stages of the SC of their products ${ }^{5}$.

Increasingly, companies around the world are flocking to a SC as the latest methodology to reduce costs, increase customer satisfaction, better use of existing assets and build new revenue. The SC Management is the integration of these activities through improved chain to gain a sustainable competitive advantage relationship. In this definition, the management of the SC includes management information systems, procurement and purchasing, production scheduling, order processing, inventory management, storage, service customer service and after sales. It is a management approach that proposes the integration and coordination of all key business processes ranging from the end user and the initial suppliers is, in order to create and between gar values to the end user, in for ma finished products and services ${ }^{6}$.

\section{Methodology}

The methodology in four (4) phases designed to achieve specific objectives in the project. Distribution chains selected in the company of study is shavers, razors and products for skin care. The phases are as follows $s^{\frac{3.7}{7}}$ :

1. The SC and information systems used in the department of the category under study are diagnosed.

2. Activities are developed in order to identify factors and opportunities in the SC to improve the key performance indicators (ICD).

3. The process of developing proposals for improvements that would meet the overall objective of this project starts.

4. Tools and processes for implementing each of the proposals for improvement are developed.

\section{Results}

\subsection{Phase I: Diagnosis the CSPT in EMEA}

After the diagnosis of Gillette supply chains in EMEA, it is determined that all have strengths, weaknesses, opportunities and threats very similar to each other. This is because they share all Processes, Markets, Key Performance Indicators, and even demand planning staff. Because of this a unique FODA matrix, which is presented in Table 1. is developed.

Table 1. Strengths, Weaknesses, Opportunities, And Threats (SWOT) matrix CSPT in EMEA

\begin{tabular}{|l|l|}
\hline Strengths & opportunities \\
\hline $\begin{array}{l}\text { Effective monitoring } \\
\text { processes and inventory } \\
\text { control have }\end{array}$ & $\begin{array}{l}\text { Possibility of reduction } \\
\text { policies boldest inventory. }\end{array}$ \\
\hline $\begin{array}{l}\text { They have remained good } \\
\text { Service Levels }\end{array}$ & $\begin{array}{l}\text { There is support from } \\
\text { senior managers to promote } \\
\text { improvements. }\end{array}$ \\
\hline $\begin{array}{l}\text { There is close relationship } \\
\text { between the Department of } \\
\text { Planning Supplies Category } \\
\text { (DPCSC) and plants }\end{array}$ & $\begin{array}{l}\text { The DPCSC is looking for } \\
\text { new processes to reduce } \\
\text { inventory. }\end{array}$ \\
\hline
\end{tabular}




\begin{tabular}{|l|l|}
\hline weaknesses & threats \\
\hline $\begin{array}{l}\text { Currently there are } \\
\text { budgetary constraints that } \\
\text { limit contingency plans }\end{array}$ & $\begin{array}{l}\text { There is a risk of major job } \\
\text { cuts if the global economic } \\
\text { crisis is maintained. }\end{array}$ \\
\hline $\begin{array}{l}\text { High levels of inventory Low } \\
\text { Income (UBI) that lower } \\
\text { performance CSPT Gillette }\end{array}$ & $\begin{array}{l}\text { There is a risk of coincidence } \\
\text { of holiday periods Plant } \\
\text { employees, ODM and } \\
\text { DPCSC. }\end{array}$ \\
\hline $\begin{array}{l}\text { Difficulty levels decrease INP } \\
\text { and Excess }\end{array}$ & $\begin{array}{l}\text { Occasionally failures have } \\
\text { occurred in production } \\
\text { due to quality problems of } \\
\text { products. }\end{array}$ \\
\hline
\end{tabular}

\subsection{Phase II: Identifying Key Factors to Improve the CSPT in EMEA.}

Based on the analyses performed in the previous stages the following factors that allow improved inventory levels and service were identified ${ }^{8}$ :

Excess Inventory reduction: improved this factor will improve International Bittering Units (IBU) levels as well as reduce overall inventory levels without risk of affecting the indicator Percentage Of Completed orders (POC).

Forecast Inactive Inventory: the possibility to provide the appearance of Inactive Inventory lets you take measures to eliminate them before it appears. This reduces INP indicators, IBU and reduce inventory in general.

Recalculation Inventory Security and policy adjustments of inventories: the improvement of this factor would make better use of safety stock while improving service indicators as the mathematical model used properly comply with the parameters and requirements supply chain. In turn, allow control processes and continuous monitoring to handle unforeseen will be shorter, as it would have a Safety Stock (SS) that is mathematically designed to manage the volatility correctly and so time would free staff DPCSC and plant to focus on other activities.

Setting Cyclical Inventory levels for Millennium Development Goals (MDGs): the setting of this factor would reduce overall inventory levels and prevent the creation of larger amounts of Inactive Inventory improving indicators INP and IBU.

\subsection{Phase III: Improvement Proposals for CSPT in EMEA}

This stage is divided into four (4) parts. Each part focuses on improving one of the factors identified in the previous phase.

\subsubsection{Excess Redistribution Process}

The distribution process requires a computational tool to identify when a Stock Keeping Unit (SKU) is in excess in this application MDGs and another MDGs.

The process is based on the following steps:

1. SKUs candidates for redistribution are determined: from the DPCSC computational tool is used to determine which SKUs could be distributed as there are excess levels on one side and demand in the Central Supply Depot.

2. The MDGs are selected to redistribute: these MDGs must have more than 67,000 UM in merchandise to be distributed and prioritized according to the value of redistribution. This is due to parameters given by the Department of Finance that is responsible for paying redistribution.

3. Planner's production plants as well as planners demand in selected MDGs: the SKU candidates to be redeployed for approval are sent.

4. The amounts are determined to be redistributed: planners agree on the amount to be redeployed and Redistribution Authorization is created from the DPCSC to start running.

5. The Original Design Manufacturer (ODM) organizes the shipment of the products: after receiving authorization Redistribution, the MDGs must make the shipment of the products within ten (10) business days.

6. This process is repeated monthly.

\subsubsection{Process Inventory Elimination Preventive Orange}

This proposal seeks to specifically attack the Orange Inactive Inventory.

For this proposed development is necessary computational tool to identify when new inventory orange to verify the date on which the demand for the product stops appears $\stackrel{9}{\text {. }}$

The process consists of the following:

1. The tool runs and SKUs representing identify possible risks of INP Orange.

2. The cause of risk identified with planners demand the MDGs is verified.

3. The MDGs should formulate a plan for the elimination of that future INP and present it to DPCSC in a period not exceeding two (2) weeks. 
4. The plan developed by the MDGs and monitored its progress weekly runs.

\subsubsection{Reprogramming the Cyclical Inventory}

This improvement is proposed reprogramming Cyclical Inventory levels in information systems. The ultimate goal is that the maximum IC in the MDGs corresponds to the days before the next replenishment of inventory, or what is equal to the frequency of shipments to the MDGs. However, the process must be gradual so as not to affect the ICD once.

The action plan would be:

1. Maximum parameter Inventory (Imax) is reduced by two (2) days of demand.

2. ICD, specifically the INP and IBU are readjusted.

3. Once adjusted indicators in two (2) weeks, the MDGs must develop a plan for the elimination of INP that could be generated with the parameter change.

4. It runs the plan developed

5. The process is repeated until the IMax parameter is equal to the send to the MDGs.

\subsubsection{Correction Calculation and Inventory Policy}

This proposed improvement is recalculating inventory levels Security in the MDGs and also proposes changing the inventory policy managed in the Central Supply Depot Reading (ACSR) so that they can maintain levels of IS to enable protect the store market volatility. However, modification of the IS may involve significant risks in service levels. Because of that, the transition should be gradual and follow the following procedure $e^{10,11}$ :

1. Using a system capable of modelling a SC multi-step to establish appropriate inventory levels in the Central Supply Depot

2. Add levels of IS in the Central Supply Depot without changing the levels in the MDGs.

3. After three (3) months, IS levels are reduced in the MDGs at a midpoint between the recommendations of the tool and the current levels of IS.

4. It verified that in the next three (3) months have no risk in the service attributable to changes, and this condition be fulfilled proceed to step 5 .

5. The levels in the MDGs are reduced to the recommendation of the tool SKU except where risks have been presented in the level of service.

\subsection{Phase IV: Implementing Improvement Proposals}

This process applies to the SC shavers and razor blades as pilot phase. The first tests were carried out in the MDGs in Italy, Europe South East, UK and France.

\section{Conclusions}

During pilot tests Redistribution Process the following results were obtained:

Process Redistribution Excess: is an achieved redistribute 341 pallet of merchandise related to Supply Chain Razors and razor blades valued at $984,000 \mathrm{CU}$ and reduce the cost of transporting an additional 23 pallets that had to be re-packaged. These results are achieved in a period of only 14 weeks.

Process Inventory Elimination Preventive Orange: 529.500UM preventing future Inactive Inventory is achieved in a period of 8 weeks, representing preventing an increase of $16 \%$ over the boundaries of the established goal.

\section{References}

1. Pundoor G. SC simulation models for evaluating the impact of rescheduling frequencies [Master thesis]. Institute for Systems Research. University of Maryland. 2002; 40:23-41.

2. Cannella S, Ciancimino E, Framiñan JM, Disney S. The four types of supply chains. Universia Business Review Second Quarter; 2010.

3. Anderson DL, Britt FE, Favre DJ. The seven principles of SC management, Logistics Management; 2015.

4. Cooper MC, Lambert DM, Pagh JD. SC management: more than a new name for logistics. The International Journal of Logistics Management. 2015; 5(1):45-85.

5. Holweg M, Disney SM, Holmström J, Småros J. SC collaboration: making sense of the strategy continuum. European Management Journal. 2015; 23(2):170-81.

6. Jiao JR, Xiao Y, Arun K. An agent-based framework for collaborative negotiation in the manufacturing SC overall network. Robotics and Computer-Integrated Manufacturing. 2015 Jun; 2:239-55.

7. Soman CA, Donk PV, Gaalman G. Combined maketo-order make-to-stock in a food production system. International Journal of Production Economics. 2004; 90:223-35.

8. Abhyankar HS, Graves S. Creating an inventory for Markov modulated poisson hedge demand: an application 
and model. Manufacturing and Service Operations Management. 2001; 3:306-20.

9. Amelec V. Validation of strategies to reduce exhausted shelf products in a pharmaceutical chain. Advanced Science Letters. 2015 May; 21(5):1403-5.

10. Amelec V. Increased efficiency in a company of development of technological solutions in the areas commercial and of consultancy. Advanced Science Letters. 2015 May; 21(5):1406-8.

11. Amelec V. Validation process container for distribution of articles for home. Advanced Science Letters. 2015 Jun; 21:1413-5. 